\title{
In Vitro Evaluation of the Inhibitory Activity of Different Selenium Chemical Forms on the Growth of a Fusarium proliferatum Strain Isolated from Rice Seedlings
}

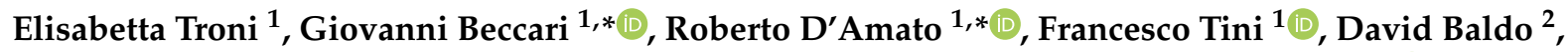 \\ Maria Teresa Senatore ${ }^{2}$, Gian Maria Beone ${ }^{3}$, Maria Chiara Fontanella ${ }^{3}$, Antonio Prodi ${ }^{2}{ }^{(\mathbb{D}}$, Daniela Businelli ${ }^{1}$ \\ and Lorenzo Covarelli ${ }^{1}$ (B)
}

check for

updates

Citation: Troni, E.; Beccari, G.;

D'Amato, R.; Tini, F.; Baldo, D.;

Senatore, M.T.; Beone, G.M.;

Fontanella, M.C.; Prodi, A.; Businelli,

D.; et al. In Vitro Evaluation of the

Inhibitory Activity of Different

Selenium Chemical Forms on the

Growth of a Fusarium proliferatum Strain Isolated from Rice Seedlings.

Plants 2021, 10, 1725. https://

doi.org/10.3390/plants10081725

Academic Editors: Dragana Šunjka and Špela Mechora

Received: 2 August 2021

Accepted: 17 August 2021

Published: 20 August 2021

Publisher's Note: MDPI stays neutral with regard to jurisdictional claims in published maps and institutional affiliations.

Copyright: (c) 2021 by the authors. Licensee MDPI, Basel, Switzerland. This article is an open access article distributed under the terms and conditions of the Creative Commons Attribution (CC BY) license (https:/ / creativecommons.org/licenses/by/ $4.0 /)$
1 Department of Agricultural, Food and Environmental Sciences, University of Perugia, 06121 Perugia, Italy; elisabetta8891@gmail.com (E.T.); francesco.tini@collaboratori.unipg.it (F.T.); daniela.businelli@unipg.it (D.B.); lorenzo.covarelli@unipg.it (L.C.)

2 Department of Agricultural and Food Sciences, Alma Mater Studiorum University of Bologna, 40127 Bologna, Italy; david.baldo@unibo.it (D.B.); mariateresa.senatore@unibo.it (M.T.S.); antonio.prodi@unibo.it (A.P.)

3 Department for Sustainable Food Process, Catholic University of the Sacred Heart of Piacenza, 29122 Piacenza, Italy; gian.beone@unicatt.it (G.M.B.); mariachiara.fontanella@unicatt.it (M.C.F.)

* Correspondence: giovanni.beccari@unipg.it (G.B.); roberto.damato@unipg.it (R.D.)

\begin{abstract}
In this study, the in vitro effects of different Se concentrations (5, 10, 15, 20, and $100 \mathrm{mg} \mathrm{kg}^{-1}$ ) from different Se forms (sodium selenite, sodium selenate, selenomethionine, and selenocystine) on the development of a Fusarium proliferatum strain isolated from rice were investigated. A concentration-dependent effect was detected. Se reduced fungal growth starting from $10 \mathrm{mg} \mathrm{kg}^{-1}$ and increasing the concentration $\left(15,20\right.$, and $\left.100 \mathrm{mg} \mathrm{kg}^{-1}\right)$ enhanced the inhibitory effect. Se bioactivity was also chemical form dependent. Selenocystine was found to be the most effective at the lowest concentration $\left(5 \mathrm{mg} \mathrm{kg}^{-1}\right)$. Complete growth inhibition was observed at $20 \mathrm{mg} \mathrm{kg}^{-1}$ of Se from selenite, selenomethionine, and selenocystine. Se speciation analysis revealed that fungus was able to change the Se speciation when the lowest Se concentration was applied. Scanning Electron Microscopy showed an alteration of the fungal morphology induced by Se. Considering that the inorganic forms have a higher solubility in water and are cheaper than organic forms, $20 \mathrm{mg} \mathrm{kg}^{-1}$ of Se from selenite can be suggested as the best combination suitable to inhibit F. proliferatum strain. The addition of low concentrations of Se from selenite to conventional fungicides may be a promising alternative approach for the control of Fusarium species.
\end{abstract}

Keywords: fungi; Fusarium; selenium; micronutrient; inhibition; bioactivity

\section{Introduction}

Selenium (Se) is an essential micronutrient for humans and animals, and is involved in numerous biological processes, such as cellular response to oxidative stress, cellular differentiation, redox signaling, and protein folding [1-3]. More than 25 Se-containing proteins have been identified in mammals, having a role in the regulation of redox processes. Among Se proteins, Se is a crucial component of glutathione peroxidase, whose main biological role is to protect against oxidative damage by reducing free hydrogen peroxide to water and lipid hydroperoxides to their corresponding alcohols [4].

In addition to humans and animals, Se is also beneficial to plants when applied at low concentrations [5-8]. For example, Se contributes to the control of water status [9], prevents oxidative stress, delays senescence, and promotes growth [10]. Due to this experimental evidence, numerous studies have investigated Se-biofortification strategies for providing plant protection against abiotic stresses and, at the same time, when possible, beneficial food for human health [11-13]. As demonstrated for many other nutrients, Se 
also shows a U-shaped relationship between concentration in living organisms and the risk of deficiency toxicity that occurs both below and above the physiological range, which is very narrow $[3,14]$. Furthermore, Se effects on living organisms are not only concentration dependent but are also related to its chemical form and its bioavailability [15].

Depending on certain experimental conditions (i.e., application mode, concentration, form, and application timing), Se is beneficial to plants and, at the same time, detrimental to plant pathogens [16-18]. For this reason, the activity and role of Se within a plantpathogen interaction are worthy of more in-depth elucidation. To date, several studies concerning the use of Se salt treatment for the control of a range of plant pathogens have been undertaken, such as, Aspergillus funiculosus, Alternaria tenuis, Fusarium spp. and Fusarium graminearum in artificial media [19-21]; Fusarium spp. and Alternaria brassicicola in Indian mustard [22]; Fusarium oxysporum f. sp. lycopersici in tomato [23]; Penicillium expansum in artificial media [18]; Botrytis cinerea in tomato [24]; and F. graminearum in wheat [21]. Other studies showed the Se protective effect in plants against the activity of mycotoxins, such as zearalenone $[25,26]$ and aflatoxin $B_{1}$ [27]. The in vitro and in vivo ability of Se to reduce the deoxynivalenol (DON) production by F. graminearum was also explored [21]. Additionally, in soil, Se was found to enhance the microbiome diversities and the relative abundance of Plant Growth Promoting Bacteria (PGPB), while reducing the number of pathogenic fungi [28].

These results indicate that Se might serve as a potential alternative to synthetic fungicides for the control of certain plant diseases caused by several fungal pathogens [18].

In a previous study [29] on rice (Oryza sativa L.) seedlings (variety Selenium) cultivated in a hydroponic system in the presence of half-strength Hoagland solution [30], browning of stem bases was detected in more than $50 \%$ of total plants. Interestingly, the rice seedlings grown with the same method but in the presence of a Se salt (sodium selenite at a concentration of $20 \mathrm{mg} \mathrm{L}^{-1}$ of Se) showed a noticeably lower presence of these symptoms (observed only in approximately $5 \%$ of total plants). This observation, as successively described in the present paper, led us to identify the fungal microorganism associated with these symptoms as belonging to the species Fusarium proliferatum, a member of the Fusarium fujikuroi species complex (FFSC), a group of 40 closely related Fusarium species defined by morphological traits, sexual compatibility, and DNA-based phylogenetic analysis [31-33]. F. proliferatum is a globally widespread causal agent of diseases of various economically important plants including staple crops such as cereals. F. proliferatum is mostly found to colonize maize [34], but has also been isolated from rice [35,36], wheat [33], sorghum, millet [37,38], asparagus [39], garlic [40], and date palm [41]. In rice, F. proliferatum is a well-known pathogen associated with Bakanea disease. This seed-borne disease is also caused, in addition to F. proliferatum, by other species belonging to FFSC, such as Fusarium fujikuroi and Fusarium verticillioides. The typical symptoms of Bakanae disease are seedling blight, root and crown rot, pale green to yellowing of foliage, chlorotic leaves, and abnormal elongation $[36,42,43]$.

The presence of F. proliferatum in plants is also a potential risk to animal and human health because of its ability to biosynthesize several mycotoxins, such as fumonisins [44]. In particular, maize and, to a lesser extent, rice, are the matrices in which natural contaminations of this mycotoxin are more common [45].

Due to the global importance of both F. proliferatum and the host (rice) from which it has been isolated, and because, to the best of our knowledge, no studies have been conducted on the effect of Se against F. proliferatum, in the present study we investigated the in vitro effect of various Se concentrations $\left(5,10,15,20\right.$, and $100 \mathrm{mg} \mathrm{kg}^{-1}$ of Se) from four different Se chemical forms (sodium selenite, sodium selenate, selenomethionine (Se-Met), and selenocystine (Se-Cys)) on the development of a F. proliferatum strain isolated from rice seedlings. Additionally, a Se speciation analysis was performed to obtain information on the occurrence of Se metabolites and their distribution, as a consequence of Se bioconversion operated by the fungus. Finally, Scanning Electron Microscopy (SEM) analysis 
was also carried out to investigate the possible modifications induced by Se on the hyphal morphology of F. proliferatum.

As a result, the best combination of Se form and Se concentration suitable for the in vitro inhibition of the development of $F$. proliferatum is described. In addition, the obtained results were found to be useful for the hypothesis of new and alternative approaches to manage F. proliferatum infections of rice and other cereal crops, perhaps coupled with a Se-biofortification strategy [46] of grains destined for human and animal food products.

\section{Results}

\subsection{Identification of the F. proliferatum Strain PG-CH1 Isolated from Rice Seedlings}

The strain PG-CH1, obtained from rice seedlings, was identified as F. proliferatum showing a similarity score of $>99 \%$ with the reference sequences of the same species deposited on NCBI and Fusarium MLST databases. The identification was also confirmed by phylogenetic analysis (Figure 1) based on a single locus dataset of translation elongation factor $1 \alpha(t e f 1 \alpha)$ partial sequences (631 bp). The strain PG-CH1 clustered together with the reference strain F. proliferatum G18SXS9-2 (Accession Number MK952837) and Gibberella intermedia S1S (sexual stage of F. proliferatum; Accession Number JN092349) showed high bootstrap support (95\%).

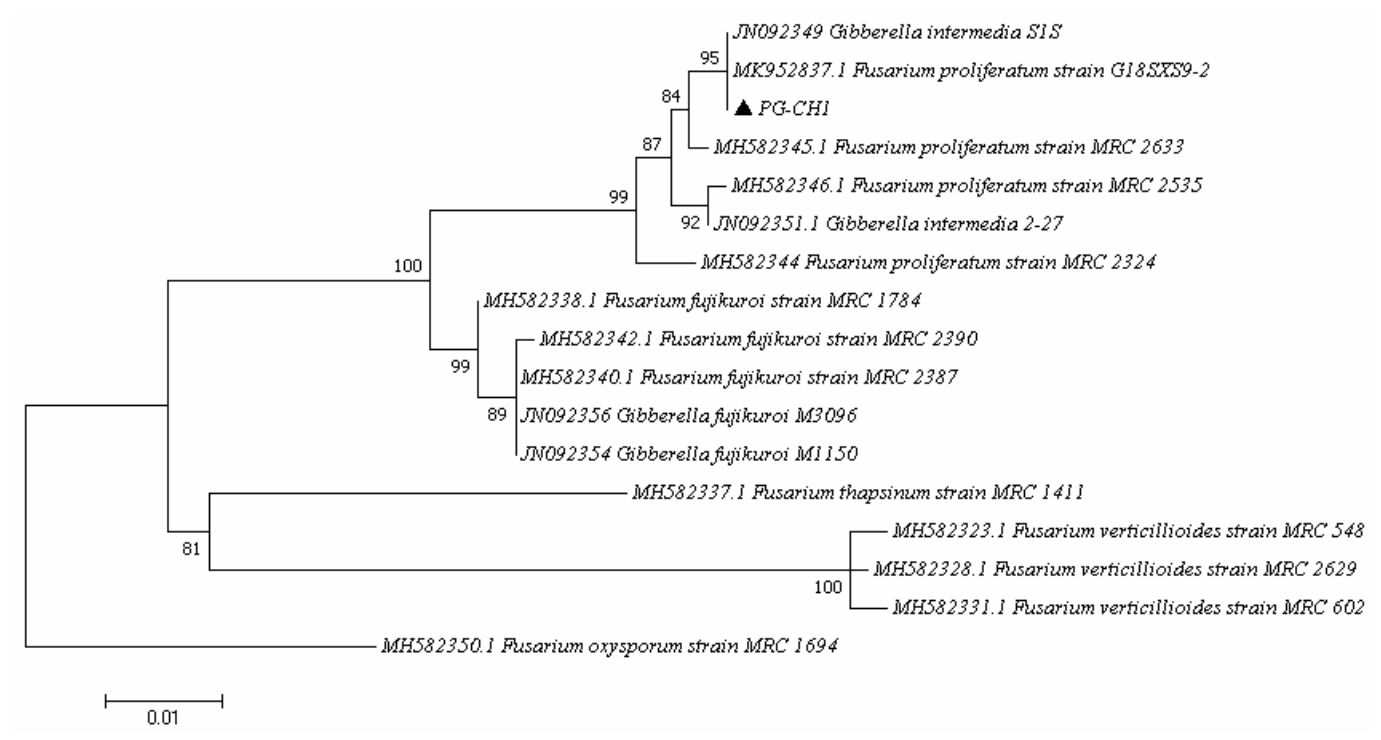

Figure 1. Phylogenetic relationship of PG-CH1 strain (triangle) and members of the Fusarium fujikuroi species complex shown in a maximum likelihood dendrogram based on the Kimura 2-parameter model. The tree with the highest log likelihood (-1567.09) is shown. Bootstrap values are indicated above the branch nodes. A discrete Gamma distribution was used to model evolutionary rate differences among sites.

\subsection{The In Vitro Inhibitory Activity of Different Se Forms on F. proliferatum Strain PG-CH1 Growth}

One representative image for each treatment (untreated or treated with Se from different forms and concentrations) is shown in Figure 2, in which the in vitro inhibitory activity of Se on F. proliferatum strain PG-CH1 colony growth on Potato Dextrose Agar (PDA) is reported. In combination with the growth reduction, as can be inferred from Figure 2, an alteration induced by Se on the morphology of F. proliferatum strain PG-CH1 colonies was also observed. In particular, a lower cottony texture and a lower mycelium density, in addition to a more intense red pigmentation in the central area of the colony, were visible in the presence of Se in comparison to the untreated control. These morphological modifications were macroscopically more appreciable in the presence of lower Se concentrations $\left(5-10 \mathrm{mg} \mathrm{kg}^{-1}\right)$ that allowed a certain colony development. Interestingly, the presence of Se from selenate induced a considerable mycelium ramification (Figure $2 b$ ) that was not detected in the presence of Se from other chemical forms. To improve clarity, please note 
that the ramification was considered for radial growth measurement. Data relative to radial growth reduction in F. proliferatum strain PG-CH1 colonies concerning the untreated control $\left(0 \mathrm{mg} \mathrm{kg}^{-1}\right.$ of Se), measured after 10 days of incubation at $22 \pm 2{ }^{\circ} \mathrm{C}$ in the dark in the presence of various Se concentrations $\left(5,10,15,20\right.$, and $100 \mathrm{mg} \mathrm{kg}^{-1}$ ) from different Se forms (selenite, selenate, Se-Met, and Se-Cys), are summarized in Figure 3.

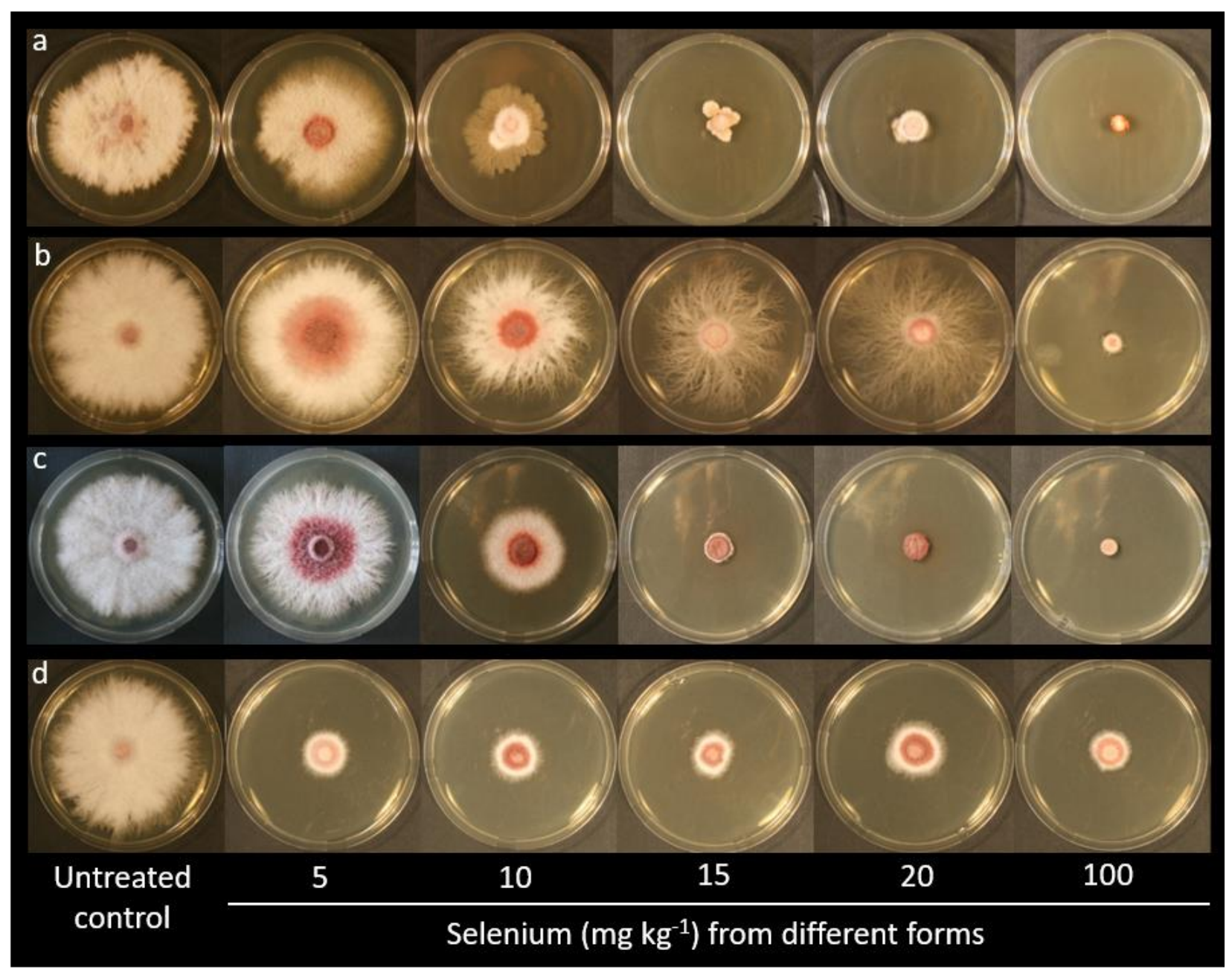

Figure 2. Effect of increasing selenium concentrations from different selenium forms on the colony development of Fusarium proliferatum strain PG-CH1 after 10 days of incubation at $22 \pm 2{ }^{\circ} \mathrm{C}$ in the dark in comparison to the untreated control. Selenite (a), selenate $(\mathbf{b})$, selenomethionine $(\mathbf{c})$, selenocystine $(\mathbf{d})$.

Significant differences in radial growth reduction in F. proliferatum strain PG-CH1 colonies relative to the untreated control $\left(0 \mathrm{mg} \mathrm{kg}^{-1}\right.$ of Se) were detected both within a Se form for different concentrations and within a Se concentration for different Se forms. Focusing the attention on Se from selenite (Figure 3), the inhibitory activity of $5 \mathrm{mg} \mathrm{kg}^{-1}$ concentration was significantly lower $(p<0.05)$ than those caused by all other concentrations, whereas Se concentrations of 15,20 , and $100 \mathrm{mg} \mathrm{kg}^{-1}$ showed a significantly higher inhibitory activity $(p<0.05)$ than the concentration of $10 \mathrm{mg} \mathrm{kg}^{-1}$. The same significant $(p<0.05)$ gradient described for selenite was observed for Se-Met (Figure 3). In contrast, regarding Se from selenate (Figure 3 ), the inhibitory activity caused by Se concentrations of $5,10,15$, and $20 \mathrm{mg} \mathrm{kg}^{-1}$ was not significantly different ( $\left.p>0.05\right)$. Only the highest Se concentration $\left(100 \mathrm{mg} \mathrm{kg}^{-1}\right)$ showed a significant effect $(p<0.05)$ on the reduction in F. proliferatum strain PG-CH1 growth in comparison to the inhibition caused by all other concentrations. 


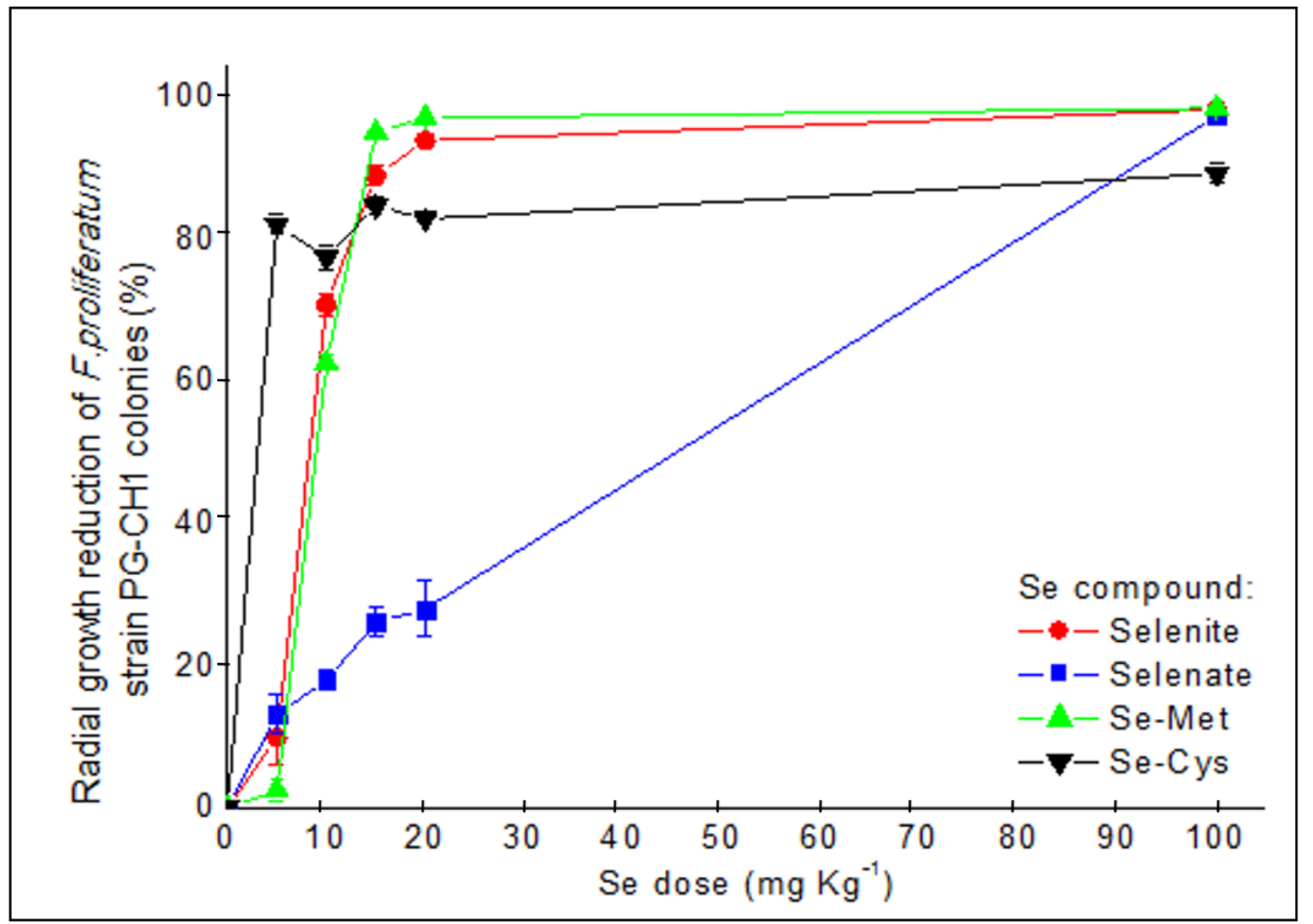

\begin{tabular}{|c|c|c|c|c|}
\hline \multirow{2}{*}{$\begin{array}{c}\text { Se dose } \\
\left(\mathbf{m g ~ k g}^{-\mathbf{1}} \mathbf{)}\right.\end{array}$} & \multicolumn{3}{|c|}{ Radial growth reduction of $\boldsymbol{F}$. proliferatum strain PG-CH1 colonies (\%) } \\
\cline { 2 - 5 } & Selenite & Selenate & Se-Met & Se-Cys \\
\hline $\mathbf{5}$ & $9.98 \pm 7.44 \mathrm{Aa}$ & $13.18 \pm 5.57 \mathrm{Aa}$ & $2.48 \pm 2.91 \mathrm{Aa}$ & $82.21 \pm 2.78 \mathrm{Ab}$ \\
\hline $\mathbf{1 0}$ & $70.94 \pm 3.05 \mathrm{Bac}$ & $18.00 \pm 2.83 \mathrm{Ab}$ & $62.76 \pm 1.95 \mathrm{Bc}$ & $77.54 \pm 3.36 \mathrm{Aa}$ \\
\hline $\mathbf{1 5}$ & $89.07 \pm 2.59 \mathrm{Ca}$ & $26.14 \pm 4.04 \mathrm{Ab}$ & $95.17 \pm 0.60 \mathrm{Ca}$ & $84.89 \pm 2.22 \mathrm{Aa}$ \\
\hline $\mathbf{2 0}$ & $94.09 \pm 0.30 \mathrm{Ca}$ & $28.06 \pm 8.01 \mathrm{Ab}$ & $97.27 \pm 0.14 \mathrm{Ca}$ & $83.02 \pm 0.68 \mathrm{Aa}$ \\
\hline $\mathbf{1 0 0}$ & $98.45 \pm 0.04 \mathrm{Ca}$ & $97.55 \pm 0.28 \mathrm{Bb}$ & $98.64 \pm 0.04 \mathrm{Ca}$ & $89.36 \pm 2.71 \mathrm{Aa}$ \\
\hline
\end{tabular}

Figure 3. Effect of five selenium (Se) concentrations (5, 10, 15, 20, and $100 \mathrm{mg} \mathrm{kg}^{-1}$ ) from sodium selenite (selenite; red circles), sodium selenate (selenate; blue squares), selenomethionine (Se-Met; green up-triangles), and selenocystine (Se-Cys; black down-triangles) on Fusarium proliferatum strain PG-CH1 colony development. The inhibitory activity was measured after 10 days of incubation at $22 \pm 2{ }^{\circ} \mathrm{C}$ in the dark and expressed as the mean ( \pm standard error) of colony radial growth reduction (\%) relative to the untreated control $\left(0 \mathrm{mg} \mathrm{kg}^{-1}\right.$ of Se), calculated according to the equation: (radial growth control - radial growth treatment $_{\text {: }}$ radial growth control $\times 100$. One-way ANOVA was used to determine statistically significant differences in radial growth of the tested strain. In the table, within a Se form $(A-C)$ or a Se concentration (a-b), means with the same letter are not significantly different at $p<0.05$ based on the Tukey Honestly Significant Difference multiple comparison test.

The growth reduction performed by Se from Se-Cys (Figure 3) was not significantly different $(p<0.05)$ across the five Se concentrations tested; that is, the inhibitory activity detected at the lowest concentration of $5 \mathrm{mg} \mathrm{kg}^{-1}$ of Se was not different from that observed following the treatment with higher Se concentrations, including that of $100 \mathrm{mg} \mathrm{kg}^{-1}$. The concentration of $5 \mathrm{mg} \mathrm{kg}^{-1}$ Se from Se-Cys showed a significantly higher $(p<0.05)$ inhibitory activity with respect to Se from all other chemical forms. Increasing the concentration to $10 \mathrm{mg} \mathrm{kg}^{-1}$ of Se from Se-Cys and selenite showed a similar $(p>0.05)$ effect 
on the growth reduction in F. proliferatum strain PG-CH1, followed by Se from Se-Met. Se inhibition activity from this last compound was, in turn, significantly lower $(p<0.05)$ than Se from Se-Cys but not significantly different $(p>0.05)$ from that observed for Se from selenite. Conversely, at this concentration, Se from selenate showed the significantly lowest $(p<0.05)$ inhibitory activity compared with that of Se from the other three forms. At the concentrations of 15 and $20 \mathrm{mg} \mathrm{kg}^{-1}$, Se from selenite, Se-Cys, and Se-Met showed a similar $(p>0.05)$ effect on fungal growth reduction, whereas Se from selenite showed, in both cases, a significantly lower $(p<0.05)$ inhibitory activity than those detected for Se from the other three chemical forms. Finally, at the highest tested concentration $\left(100 \mathrm{mg} \mathrm{kg}^{-1}\right)$, the inhibitory activity of Se from Se-Cys was significantly lower $(p<0.05)$ than those detected for Se from selenite, selenate, and Se-Met.

Summarizing, all Se treatments from different Se forms showed a certain effect on F. proliferatum strain PG-CH1. In particular, the highest inhibitory activity at the lowest concentration of Se $\left(5 \mathrm{mg} \mathrm{kg}^{-1}\right)$ tested in this experiment was caused by Se from Se-Cys, whereas increasing the concentrations $\left(10,15\right.$, and $\left.20 \mathrm{mg} \mathrm{kg}^{-1}\right)$ of Se from selenite, Se-Cys, and Se-Met showed a higher reduction in fungal colony growth than Se from selenate. Se from selenite, selenate, and Se-Met inhibited F. proliferatum strain PG-CH1 growth more than Se-Cys at $100 \mathrm{mg} \mathrm{kg}^{-1}$. The control treatment (PDA amended with $\mathrm{Na}^{+} 100 \mathrm{mg} \mathrm{kg}^{-1}$ from Sodium chloride $(\mathrm{NaCl})$ ) showed a negligible effect on the growth of F. proliferatum strain PG-CH1 colonies, because only a radial growth reduction up to $1.8 \%$ was observed (Supplementary Figure S1).

\subsection{Se Speciation}

Se speciation analysis was performed on Se-amended PDA in the presence of $F$. proliferatum strain PG-CH1, and on Se-amended PDA in the absence of F. proliferatum strain PG-CH1. In the presence of fungus, Se-speciation data showed a transformation of the applied Se form (selenite, selenate, Se-Cys, and Se-Met) in other Se chemical forms (Figure 4). Conversely, no transformation of the applied Se form was observed in the absence of F. proliferatum strain PG-CH1 (data not reported).

In general, in the presence of fungus, the observed Se transformation in other Se chemical forms was reduced by increasing Se concentration to such an extent that no conversion was detected at the highest Se concentration $\left(100 \mathrm{mg} \mathrm{kg}^{-1}\right)$. This observation suggests the capacity of the fungus to metabolize Se at low concentrations, whereas accumulation of the applied Se form occurred at the highest Se concentration. For that reason, in the following, we discuss the Se speciation results in the presence of F. proliferatum strain PG-CH1, focusing on the lowest Se concentrations applied of 5 and $10 \mathrm{mg} \mathrm{kg}^{-1}$. When inorganic Se from selenite was applied, the conversions in Se-Cys (up to 36\%) and Se-Met (up to $16 \%$ ) were mainly observed (Figure 4a); when inorganic Se from selenate was applied, the conversions in Se-Met (up to 58\%), Se-Cys (up to 16\%), and selenite (up to $8 \%$ ) occurred (Figure 4b). When organic Se from Se-Met was applied, Se speciation analysis revealed mainly the conversion in Se-Cys (up to 72\%) and a trace of selenite (up to 4\%) (Figure 4c); when Se-Cys was applied, it was converted to selenite (up to $24 \%$ ), selenate (up to $11 \%$ ), and Se-Met (up to $8 \%$ ) (Figure $4 \mathrm{~d}$ ).

To ascribe with certainty the Se transformation in other Se forms to F. proliferatum strain PG-CH1, Se speciation was also performed on PDA amended with Se in the absence of the fungus. Based on the above results (Figure 4), the lowest Se concentration (as the concentration at which the greater Se conversion into other Se forms occurred) was selected and Se speciation analysis was performed on PDA amended with $5 \mathrm{mg} \mathrm{kg}^{-1}$ of Se from selenite, selenate, Se-Cys, and Se-Met in the absence of F. proliferatum strain PG-CH1. The obtained data did not show the transformation of the applied Se form in other Se chemical forms, thus confirming that the observed Se transformations in other chemical forms were undertaken by F. proliferatum strain PG-CH1. 
a) Selenite treatment

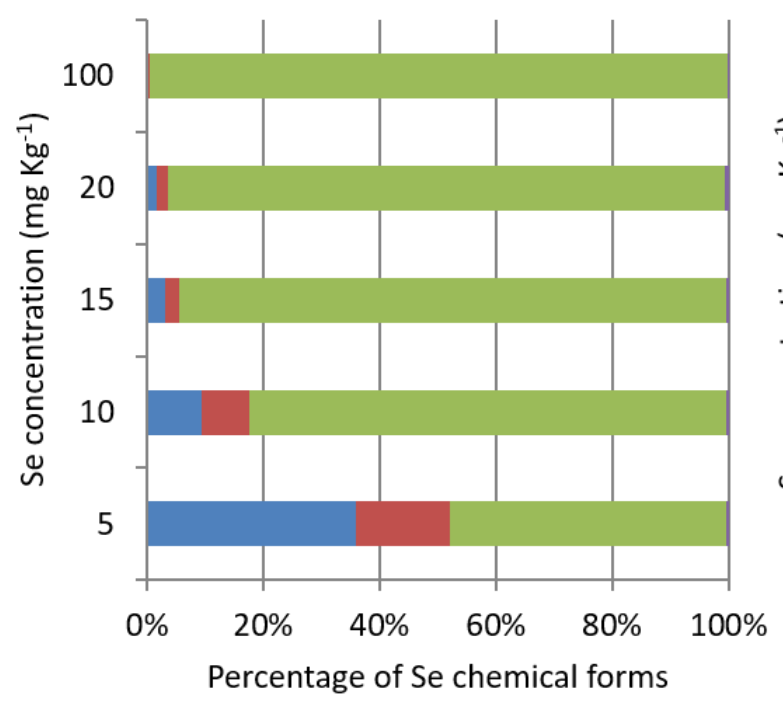

c) Se-Met treatment

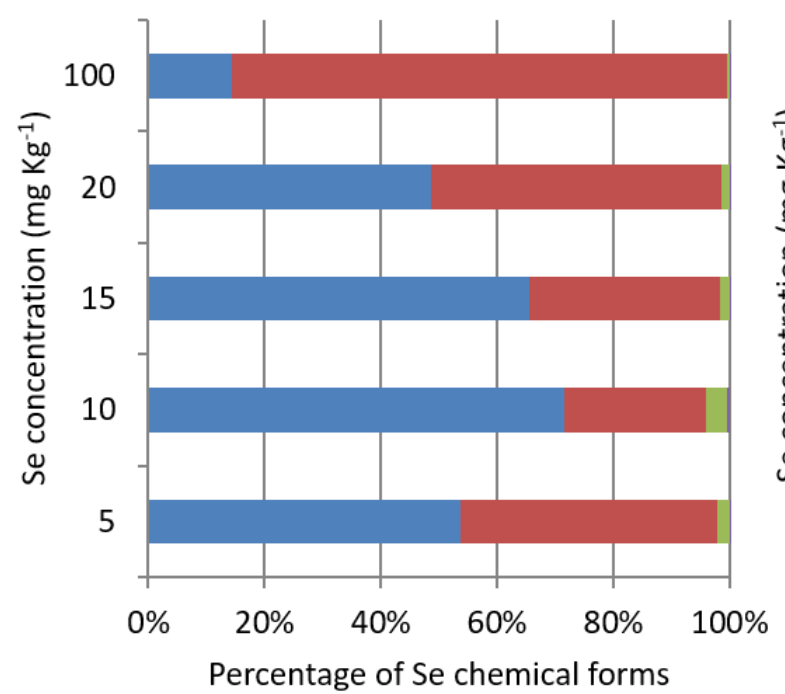

Selenite

- Selenate b) Selenate treatment

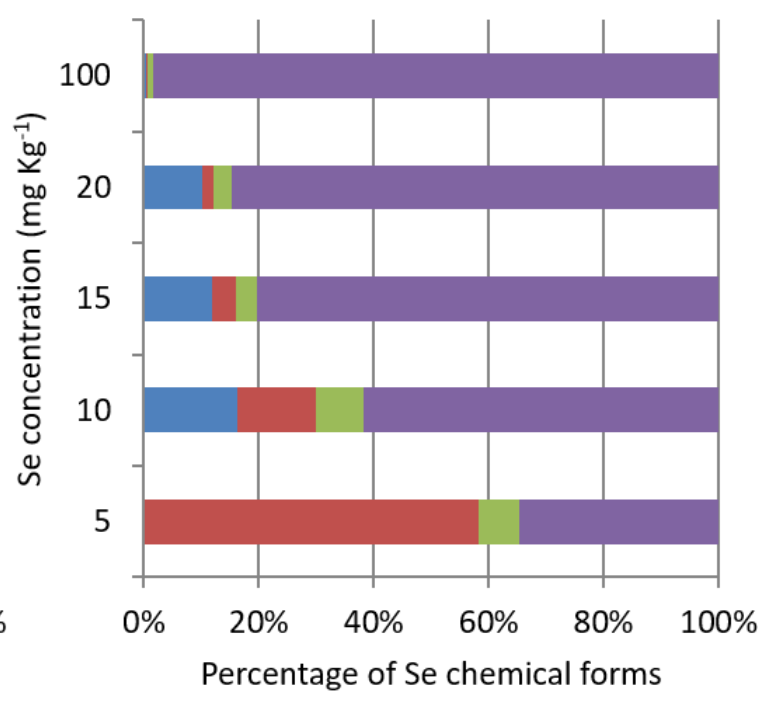

d) Se-Cys treatment

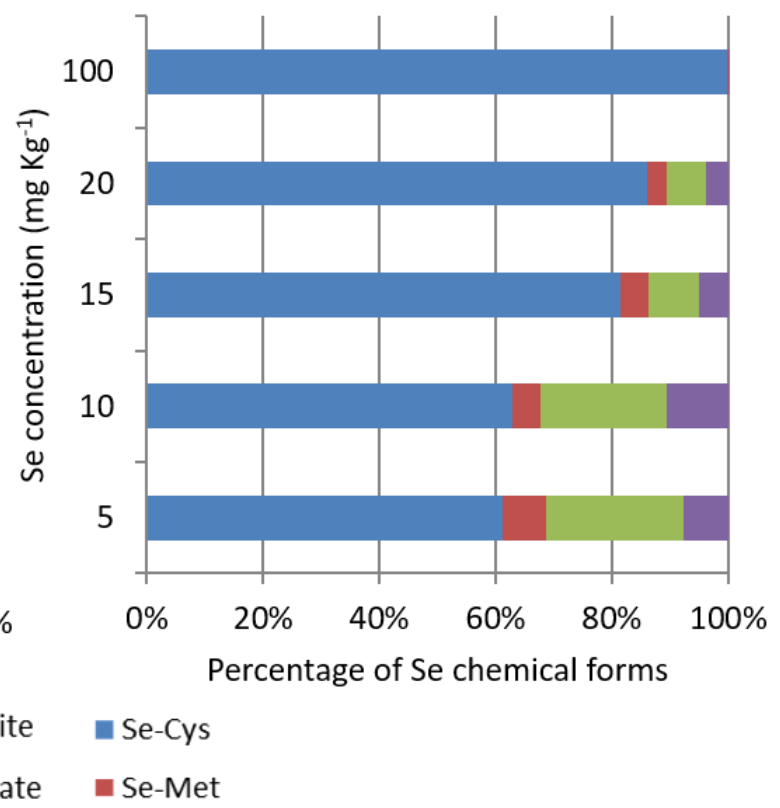

Figure 4. Selenium (Se) speciation data showing different Se chemical forms and their distribution after 10 days of incubation in the growth medium (potato dextrose agar) in the presence of Fusarium proliferatum strain PG-CH1 and following the application of increasing Se concentrations $\left(5,10,15,20\right.$, and $100 \mathrm{mg} \mathrm{kg}^{-1}$ ) as sodium selenite (selenite; a), sodium selenate (selenite; b), selenomethionine (Se-Met; c), and selenocystine (Se-Cys; d).

\subsection{Selenium (20 $\mathrm{mg} \mathrm{kg}^{-1}$ ) from Sodium Selenite Effect Observed by SEM}

Based on the results obtained for the in vitro inhibitory activity of Se from different Se forms on F. proliferatum strain PG-CH1 growth, for SEM analysis we focused our attention on the effect of $20 \mathrm{mg} \mathrm{kg}^{-1}$ of Se from selenite (Figure 5).

In general, a lower mycelium density with shorten hyphae was observed in the treated samples (Figure $5 \mathrm{~d}$ ) in comparison to the untreated ones (Figure 5a). In detail, a strong hyphal collapse was also noticed in the treated samples (Figure 5e,f) compared to the untreated samples (Figure $5 b, c)$. This observation showed additional evidence that Se from selenite at the concentration of $20 \mathrm{mg} \mathrm{kg}^{-1}$ was able to determine the inhibition of $F$. proliferatum strain PG-CH1 growth, which was also manifested by the alteration of fungal hyphae morphology and density. 

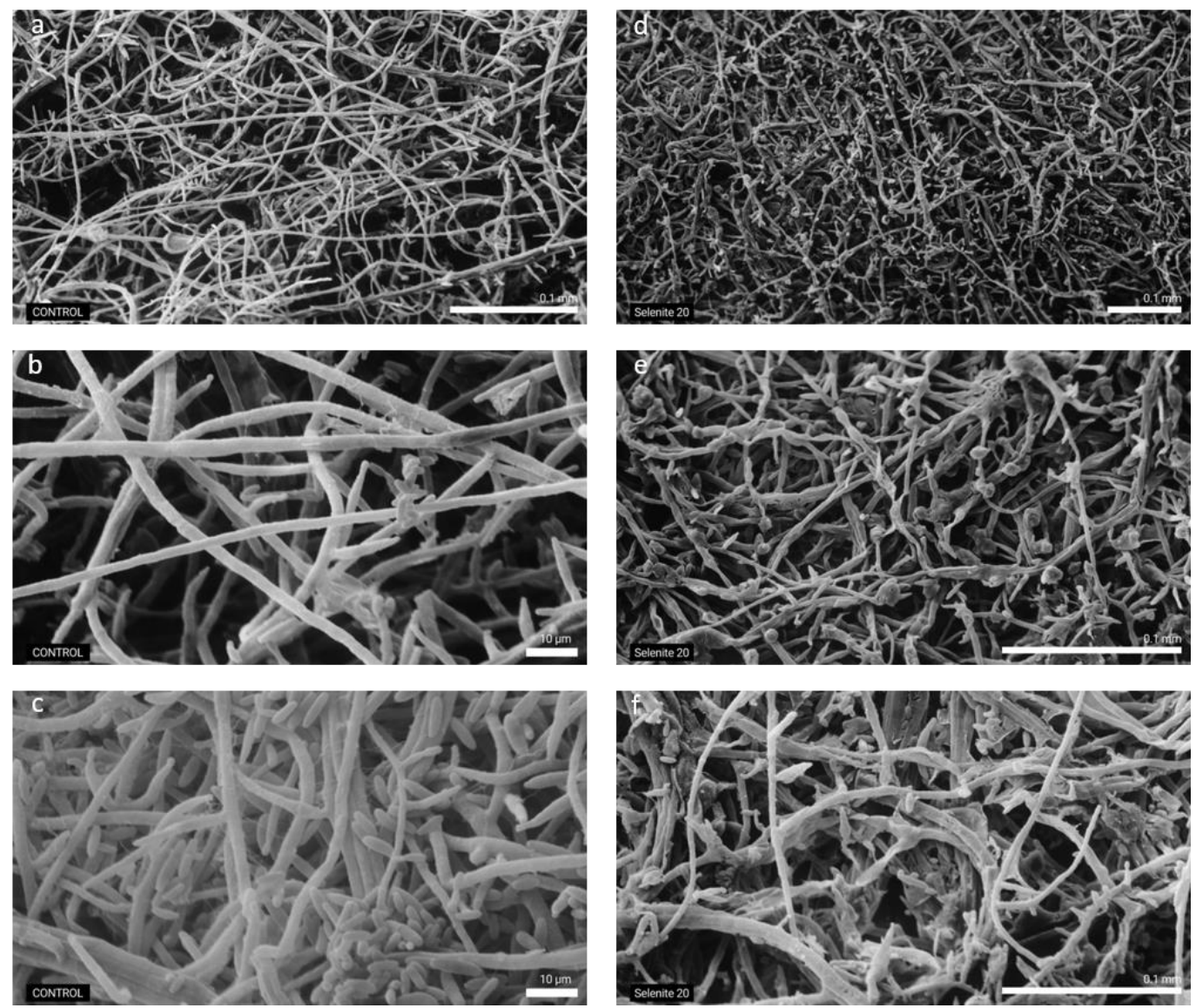

Figure 5. Scanning Electron Microscopy images showing Fusarium proliferatum strain PG-CH1 hyphae grown for 10 days on potato dextrose agar (PDA) not amended with selenium (Se) (labelled as control) (a-c) and on PDA amended with $20 \mathrm{mg} \mathrm{kg}^{-1}$ of Se as sodium selenite (selenite; labelled as selenite 20) (d-f). The effect of $20 \mathrm{mg} \mathrm{kg}^{-1}$ of Se as selenite caused appreciable modifications in the morphology and density of $F$. proliferatum strain PG-CH1 hyphae (d-f) in comparison to the untreated control $(\mathbf{a}-\mathbf{c})$.

\section{Discussion}

This study aimed to assess the inhibitory activity of Se toward F. proliferatum strain PG-CH1 isolated from rice seedlings. Several studies $[3,14,15]$ showed that Se effects on living organisms depend on Se concentration, in addition to the Se chemical form and bioavailability. Se is one of the few non-metals exhibiting variable oxidation statesselenate $(+6)$, selenite $(+4)$, elemental Se $(0)$, and selenide $(-2)$. Moreover, the distribution of the valence states in a given environment strongly depends on several parameters, such as biological interactions, $\mathrm{pH}$, redox conditions, the solubility of its salts, the chemical complex of soluble and solid ligands, reaction kinetics, and temperature [47,48]. Consequently, Se naturally occurs in different chemical forms. Among these, in living organisms, Se is found both in inorganic forms (mainly as selenite and selenate) and organic forms (mainly as Se-Cys and Se-Met) [49]. In general, it has been reported that organic Se forms have less toxicity compared to inorganic forms in living organisms [3].

Based on the above, in this study, four different Se chemical forms (inorganic Se as selenite and selenate; organic Se as Se-Met and Se-Cys) in the concentration range $5-100 \mathrm{mg} \mathrm{kg}^{-1}$ of Se were tested. This concentration range was selected after a preliminary test in which F. proliferatum strain PG-CH1 was grown on PDA amended with Se concentration (from selenite) in the range $1-200 \mathrm{mg} \mathrm{kg}^{-1}$. A negligible effect on the reduction in the fungal growth was observed up to $5 \mathrm{mg} \mathrm{kg}^{-1}$ of Se, whereas the fungal growth was almost completely inhibited at $100 \mathrm{mg} \mathrm{kg}^{-1}$ of Se. 
In general, in our experimental conditions, a significant in vitro concentration-dependent Se bioactivity from different Se forms towards F. proliferatum strain PG-CH1 was observed. For example, with the exception of Se from selenate, Se reduced $(>60 \%)$ the F. proliferatum strain PG-CH1 growth relative to the untreated control starting from the concentration of $10 \mathrm{mg} \mathrm{kg}^{-1}$. Additionally, by increasing Se concentration to 15 and $20 \mathrm{mg} \mathrm{kg}^{-1}$, the growth reduction caused by Se from selenite, Se-Met, and Se-Cys exceeded 80\%. Finally, at the concentration of $100 \mathrm{mg} \mathrm{kg}^{-1}$ of Se, F. proliferatum strain PG-CH1growth was almost completely inhibited (growth reduction of $\geq 89 \%$ ), regardless of the applied Se form. An in vitro concentration-dependent activity of Se was previously reported to inhibit $A$. funiculosis, A. tenuis, and Fusarium spp. (Se from selenite) [19], P. expansum (Se from selenite) [18], B. cinerea (Se from selenite) [50], A. brassicicola, Fusarium spp. (Se from selenate) [22], and F. graminearum (Se from selenite, selenate, Se-Met, and Se-Cys) [21] growth. In addition to reporting that the effect of Se (from selenite) against a strain of Fusarium sp. was concentration dependent, Yin et al. 2017 [51], showed that Se (from selenite) in the range $0.1-1.0 \mathrm{mg} \mathrm{kg}^{-1}$ promoted the growth of another strain belonging to the F. tricinctum species.

Moreover, the results obtained in this study showed that Se bioactivity was not only concentration dependent but, as mentioned above, also related to the Se chemical form deployed and its bioavailability. For example, Se from selenate exhibited the lowest bioactivity in up to $20 \mathrm{mg} \mathrm{kg}^{-1}$ of Se (radial growth reduction in F. proliferatum strain PG$\mathrm{CH} 1$ colonies of up to $28 \%$ ) compared to the other Se forms (percentage of radial growth reduction in F. proliferatum colonies ranged from 83 to $97 \%$ at $20 \mathrm{mg} \mathrm{kg}^{-1}$ of Se from selenite, Se-Cys, and Se-Met). Conversely, Se from Se-Cys was found to be the most effective at the lowest Se concentration (radial growth reduction in F. proliferatum colonies at $5 \mathrm{mg} \mathrm{Kg}^{-1}$ of $79.3 \%$, whereas Se from other forms reduced the growth by up to $13.1 \%$ at $5 \mathrm{mg} \mathrm{kg}^{-1}$ of Se). However, it should be recalled that, at the concentrations of 10, 15, and $20 \mathrm{mg} \mathrm{kg}^{-1}$, Se from selenate altered the morphology of $F$. proliferatum strain PG-CH1 colonies by inducing hyphae ramification and decreasing mycelium density. In addition, in vitro $\left(20-80 \mathrm{mg} \mathrm{L}^{-1}\right)$ and in planta (wheat, $20 \mathrm{mg} \mathrm{L}^{-1}$ ) effects of Se from selenite, selenate, Se-Met, and Se-Cys on fungal growth (in vitro), symptoms (in planta), and DON accumulation (in vitro and in planta) was compound dependent [21].

For further investigation of the process of growth inhibition resulting from Se supplementation to the growth medium, we performed Se speciation analysis to obtain information on the occurrence of the process of Se conversion in other chemical forms operated by F. proliferatum strain PG-CH1, or on the process of Se accumulation. No transformation of the applied Se forms occurred in the absence of F. proliferatum, whereas transformation of the applied Se forms was observed in the presence of the fungal microorganism, indicating that F. proliferatum strain PG-CH1 can metabolize Se.

In particular, the fungal capacity to transform the applied Se form was reduced by increasing Se concentration (Figure 4). Thus, we can hypothesize that the complete growth inhibition in F. proliferatum strain PG-CH1 colonies observed at $100 \mathrm{mg} \mathrm{kg}^{-1}$ of Se may be related to the accumulation (and consequent toxicity) of the applied Se forms. Concerning the lowest Se concentration applied, the observed inhibition of F. proliferatum strain PG-CH1 growth is more difficult to explain. Based on the collected speciation data and considering that the biochemistry of Se resembles that of sulfur (S) [52], we hypothesize several mechanisms as follows:

(i) The occurrence of redox processes mediated by Se (e.g., selenate reduction to selenite, see Figure $4 \mathrm{~b}$ ), which may have affected the regular physiological processes of the fungal microorganism.

(ii) The formation of organic Se compounds caused by the fungus (e.g., inorganic Se is converted to Se-Met and Se-Cys, see Figure 4a,b; Se-Met is converted to Se-Cys, see Figure 4c; Se-Cys is converted to Se-Met in small amounts, see Figure 4d), which may lead to direct incorporation of Se-Cys and Se-Met into proteins, rather than the analog sulfur-containing amino acids S-Cys and S-Met, a process previously reported in the literature $[53,54]$. In this case, the growth inhibitory effect may be ascribed to 
a different conformation of the Se proteins concerning analog $\mathrm{S}$ proteins to such an extent that a modification in protein activity should not be excluded.

(iii) The direct incorporation of the applied Se-Cys and Se-Met into proteins, a process which may explain the higher bioavailability of organic Se forms compared to inorganic Se forms.

(iv) The relationship of Se with oxidative stress [5]. For example, it is known that in certain filamentous fungi, mycelium metamorphosis, in structures that ensure fungal propagation, is induced by increased oxidative stress. Conversely, decreased oxidative stress causes a permanence of undifferentiated mycelia, and inhibition of metamorphosis and fungal propagation [55]. The extension of this theory predicts that any antioxidant (such as Se at certain doses) can stop fungal propagation by inhibiting its metamorphosis, thus acting as a natural fungicide.

To support hypotheses (ii) and (iii) for explaining the Se toxic effect, it has been reported that an excess of Se-containing proteins can have adverse effects on cellular metabolism [56]. Finally, we also noted a strong smell in the culture medium amended with Se, which may be due to the production of the volatile compound dimethyl selenide, $\left(\mathrm{CH}_{3}\right)_{2} \mathrm{Se}$, as a consequence of the detoxification mechanism of the fungus. As reported in the literature [57], the methylation of inorganic Se by microorganisms produces volatile inorganic compounds that are less toxic than inorganic forms.

Se speciation analysis is a powerful tool for detecting the final products of the Se bioconversion operated by fungi; nevertheless, Se speciation data alone are not sufficient to provide an in-depth explanation of the metabolic pathway of Se in fungal microorganisms. Several authors attempted to explain the bioavailability and toxicity of the Se forms for fungal microorganisms at the molecular and/or physiological levels. For example, Reference [58] reports that selenite and selenate are assimilated through oxyanion transporters, and, once inside the cells, they are transformed into selenide through a reductive pathway that may involve the enzyme glutathione peroxidase. In the presence of oxygen, selenide can promote the formation of reactive oxygen species (ROS), which may damage DNA, proteins, and other cellular macromolecules. Selenide is also the intermediate for the formation of selenocystine, from which selenomethionine can then be formed in organisms with a functional transsulfuration pathway. Several metabolomic studies demonstrated that selenocysteine can also be formed from selenomethionine [59,60]. However, the reason for the differences in bioavailability and toxicity possessed by different Se forms remains unknown and further studies are needed to better understand the critical metabolic processes that determine Se tolerance or toxicity. Based on the obtained results and considering that the inorganic forms of Se (selenite and selenate) have a higher solubility in water and are cheaper than organic forms (Se-Cys and Se-Met), we concluded that $20 \mathrm{mg} \mathrm{kg}^{-1}$ of Se from selenite can be suggested as the best combination of Se form and concentration suitable to in vitro inhibit the development of the considered F. proliferatum strain PG-CH1.

Even if the use of a single strain of $F$. proliferatum does not allow a general conclusion to be drawn at the species level, the results obtained may provide a basis for further investigations concerning Se effects against this polyphagous and global fungal pathogen, and for other Fusarium or fungal species. Further developments of this research can be undertaken by screening a higher number of $F$. proliferatum strains to assess the inhibitory activity of Se in a wider population context. This because not all isolates of a species may be sensitive to Se activity, and the phenomenon of Se tolerance by fungi has been previously described [61].

In addition, the activity of Se on the biosynthesis of fumonisins mycotoxins by $F$. proliferatum may also be interesting to explore, in addition to the impact of Se on the growth of other Fusarium species and their mycotoxins. Finally, these results may be also useful for evaluating the ability of Se to control F. proliferatum infections of rice in the field, in addition to this or other Fusarium species in different cereal hosts. Moreover, the addition of low concentrations of Se from selenite to conventional fungicides may be a promising alternative approach for the control of Fusarium species in different cereal hosts [62,63]. 
Many fungicides are categorized as polluting, and it can be reasonably assumed that the addition of Se may help in reducing the concentration of the chemical active ingredient by maintaining the same fungicidal efficacy and decreasing the potentially hazardous effect on the environment and human health $[17,19]$ simultaneously realizing a Se-biofortification of cereal grains [64]. Within the U-shaped range [14], Se is an essential micronutrient with beneficial effects in animals and humans [65].

\section{Materials and Methods}

\subsection{Chemicals and Reagents}

Sodium selenite $\left(\mathrm{Na}_{2} \mathrm{SeO}_{3}\right.$; selenite), sodium selenate $\left(\mathrm{Na}_{2} \mathrm{SeO}_{4}\right.$; selenate), Se-LCystine $\left(\mathrm{C}_{6} \mathrm{H}_{12} \mathrm{~N}_{2} \mathrm{O}_{4} \mathrm{Se}_{2}\right.$; Se-Cys), Se-DL-methionine $\left(\mathrm{C}_{5} \mathrm{H}_{11} \mathrm{NO}_{2} \mathrm{Se}\right.$; Se-Met $)$, Hoagland stock solution, $\mathrm{NaCl}$, streptomycin sulfate, protease, ethanol 95\%, agarose, trizma baseglacial acid acetic-ethylene diamine tetra acetic acid disodium salt dihydrate (TAE), EF1 and EF2 primers, glutaraldehyde, and phosphate buffer were all purchased from SigmaAldrich (Saint Louis, MO, USA). PDA was purchased from Biolife Italiana (Milan, Italy). Sodium hypochlorite $(\mathrm{NaClO}) 7 \%$ was purchased from Carlo Erba Reagents (Milan, Italy). RedSafe was purchased from iNtRON Biotechnology (Burlington, MA, USA). Gene Ruler1 $\mathrm{kb}$ was purchased from Thermo Fisher Scientific (Walthman, MA, USA). Dnase free sterile water was purchased from 5prime (Hilden, Germany). HyperLadder 100-1000 bp was purchased by Bioline (Cincinnati, OH, USA).

\subsection{Obtainment of Fusarium proliferatum Strain PG-CH1 from Rice Seedlings}

The F. proliferatum strain PG-CH1 used in this study was isolated from rice seedlings (variety Selenium). To assess the fungal microorganisms affecting rice seedlings, portions of symptomatic material were surface disinfected for $1 \mathrm{~min}$ with water-ethanol $95 \%-\mathrm{NaClO}$ (7\%, solution) (82:10:8\% vol.) and rinsed with sterile water for $1 \mathrm{~min}$. After the disinfection process, small pieces $(0.5 \mathrm{~cm})$ of seedling tissue were placed onto PDA supplemented with streptomycin sulfate $\left(0.16 \mathrm{~g} \mathrm{~L}^{-1}\right)$ into 5 Petri dishes $(90 \mathrm{~mm}$ diameter) containing 7 pieces each ( 7 pieces from one single seedling, 1 seedling per plate, 5 seedlings in total). The dishes were incubated at $22{ }^{\circ} \mathrm{C}$ in the dark, and after 5 days a combination of visual and stereomicroscope (SZX9, Olympus, Tokyo, Japan) observations were carried out on each piece to assess fungal development. After visual observations, fungal colonies having similar morphology on PDA showed a higher (95\%) isolation incidence.

According to colony color and shape on PDA from visual examination, in addition to the morphology of reproductive structures by microscope analysis (Axiophot, Zeiss, Oberkochen, Germany), they were considered to potentially belong to the genus Fusarium and a representative isolate (named PG-CH1) of all of those obtained was transferred onto new plates containing PDA and grown at $22{ }^{\circ} \mathrm{C}$ in the dark. After the obtainment of monosporic culture, the isolate was placed onto new PDA plates at $22{ }^{\circ} \mathrm{C}$ in the dark for two weeks. Successively, the mycelium was scraped from the PDA surface and placed into $2 \mathrm{~mL}$ sterile plastic tubes (Eppendorf, Hamburg, Germany) and stored at $-80{ }^{\circ} \mathrm{C}$. Following freeze drying with a lyophilizer (Heto Powder Dry LL3000; Thermo Fisher Scientific, Walthman, MA, USA), the mycelium was finely ground with a grinding machine (MM200, Retsch, Dusseldorf, Germany) for 6 min with a frequency of $25 \mathrm{~Hz}$.

DNA extraction was carried out using the method previously described in [66]. Extracted genomic DNA was visualized on a 1\% agarose, TAE gel in TAE buffer (1X) containing $500 \mu \mathrm{L} \mathrm{L}^{-1}$ of RedSafe. DNA fragments were separated in $10 \mathrm{~cm}$ long agarose gels, with an electrophoresis apparatus (Eppendorf) applying a tension of $110 \mathrm{~V}$ for $\sim 30 \mathrm{~min}$. Electrophoretic runs were visualized using an ultraviolet transilluminator (Euroclone, Milan, Italy). DNA concentration was estimated by comparison with Gene Ruler $1 \mathrm{~kb}$ included in each gel as a control. DNA was diluted with Dnase free sterile water for molecular biology use to obtain a concentration of $\sim 30 \mathrm{ng} \mu \mathrm{L}^{-1}$ and stored at $-20{ }^{\circ} \mathrm{C}$ until use. The DNA extracted from the Fusarium isolate was subjected to tef1 $\alpha$ gene amplification, purification, and sequencing. PCR protocol is described in [67] adopting EF1 
(ATGGGTAAGGA(A/G)GACAAGAC) and EF2 (GGA(G/A)GTACCAGT(G/C)ATCATGTT) primers [68]. PCR assays were performed on a T-100 thermal cycler (Bio-Rad, Hercules, CA, USA). The PCR fragment was visualized on TAE $1 \mathrm{X}$ agarose gel $(2 \%)$ containing $500 \mu \mathrm{L} \mathrm{L}^{-1}$ of RedSafe. The DNA fragment was separated by an electrophoresis apparatus applying a tension of $110 \mathrm{~V}$ for $\sim 40 \mathrm{~min}$. Electrophoretic runs were observed with an ultraviolet transilluminator. The size of the amplified fragment was obtained by comparison with HyperLadder 100-1000 bp. The PCR fragment was purified and sequenced by an external sequencing service (Genewiz Genomics Europe, Takeley, UK). The sequence obtained was verified by Chromatogram Explorer Lite v 4.0.0 (HeracleBiosoft srl, Mioveni, Romania, 2011) and compared to those deposited on the BLAST database (National Center for Biotechnology Information (NCBI) Basic Local Search Tool (BLAST)), available online at http:/ /blast.ncbi.nlm.nih.gov (accessed on 1 November 2018) [69], and the Fusarium MLST database (available online at http:/ / fusarium.mycobank.org/, accessed on 1 November 2018).

To further confirm the species identity, the strain PG-CH1 was subjected to phylogenetic analysis based on tef $1 \alpha$ sequences. The sequence of the PG-CH1 strain was aligned with 15 reference tef $1 \alpha$ sequences of most common pathogens associated with seedling rice diseases such as F. fujikuroi, F. verticillioides, and F. proliferatum (Table 1) [36,70]. The sequences were aligned using the Muscle Algorithm implemented in the MEGA 7 software package [71]. Phylogenetic analysis was conducted in MEGA, via maximum likelihood following the best fit model of molecular evolution as determined by Bayesian information criterion (BIC) scores. A discrete Gamma distribution was used to model evolutionary rate differences among sites. All positions with less than $90 \%$ of coverage were eliminated. Statistical support of branches was evaluated using bootstrap analysis of 1000 replicates. The out-group isolate F. oxysporum MRC 1694 (accession number MH582350) was used for rooting the tree [72].

Table 1. Fusarium spp. strains used in the phylogenetic analysis and related information.

\begin{tabular}{|c|c|c|c|c|c|c|}
\hline Strain & Species & $\begin{array}{l}\text { Species } \\
\text { Complex }\end{array}$ & Host & $\begin{array}{c}\text { Geographic } \\
\text { Origin/Substrate }\end{array}$ & $\begin{array}{c}\text { GenBank } \\
\text { Accession } \\
\text { Number }\end{array}$ & References \\
\hline MRC 548 & F. verticillioides & Fujikuroi & Maize & South Africa & MH582323.1 & [72] \\
\hline MRC 602 & F. verticillioides & Fujikuroi & Maize & South Africa & MH582331.1 & [72] \\
\hline MRC 1411 & F. tapsinum & Fujikuroi & Maize & North Carolina-USA & MH582337.1 & [72] \\
\hline MRC 1784 & F. fujikuroi & Fujikuroi & Rawcotton & Georgia, USA & MH582338.1 & [72] \\
\hline MRC 2324 & F. proliferaum & Fujikuroi & Cotton boll & Alabama, USA & MH582344.1 & [72] \\
\hline MRC 2387 & F. fujikuroi & Fujikuroi & Rice & Japan & MH582340.1 & {$[70]$} \\
\hline MRC 2390 & F. fujikuroi & Fujikuroi & Unknown & Unknown & MH582342.1 & [72] \\
\hline MRC 2535 & F. proliferatum & Fujikuroi & $\begin{array}{c}\text { River } \\
\text { sediment }\end{array}$ & Japan & MH582346.1 & [72] \\
\hline MRC 2629 & F. verticillioides & Fujikuroi & Maize & Iowa, USA & MH582328.1 & [72] \\
\hline MRC 2633 & F. proliferatum & Fujikuroi & Wheat & India & MH582345.1 & [72] \\
\hline S1S & F. proliferatum & Fujikuroi & Rice (seed) & Italy & JN092349 & [70] \\
\hline $2-27$ & F. proliferatum & Fujikuroi & Rice (seed) & Italy & JN092351 & [70] \\
\hline M3096 & F. fujikuroi & Fujikuroi & Rice & Georgia, USA & JN092356 & [70] \\
\hline M1150 & F. fujikuroi & Fujikuroi & Rice & Taiwan & JN092354 & [70] \\
\hline G18SXS9-2 & F. proliferatum & Fujikuroi & Unknown & Unknown & MK952837.1 & Unknown \\
\hline MRC 1694 & F. oxysporum & Oxysporum & Unknown & Human & MH582350.1 & [72] \\
\hline
\end{tabular}

\subsection{In Vitro Evaluation of the Inhibitory Activity of Se Forms on F. proliferatum Strain PG-CH1}

PDA was supplemented with four different Se forms (selenite, selenate, Se-Cys, and Se-Met) at five different Se concentrations (5, 10, 15, 20, and $100 \mathrm{mg} \mathrm{kg}^{-1}$ of Se). A weighed amount of each Se form was dissolved in sterile distilled water to obtain a concentrated solution of $7 \mathrm{~g} \mathrm{~L}^{-1}$ of Se. A predetermined volume $(64.3,128.6,192.8,257.1$, and $1280.0 \mu \mathrm{L}$ ) of the Se-concentrated obtained solutions was added to $20 \mathrm{~g}$ of PDA so that 
Se concentrations in the growth medium were $5,10,15,20$, and $100 \mathrm{mg} \mathrm{kg}^{-1}$. Successively, mycelium plugs ( $5 \mathrm{~mm}$ diam.) were taken from the edge of one week old F. proliferatum strain PG-CH1 colonies, developed on PDA at $22{ }^{\circ} \mathrm{C}$, in the dark. The plugs were placed onto Se amended PDA, at the center of the plate, with the mycelium side facing upwards. Untreated controls ( $0 \mathrm{mg} \mathrm{kg}^{-1}$ of Se), and control treatments with $\mathrm{NaCl}$ (as counter ions of selenite and selenate), were also included in the experiment to ascribe the observed growth reduction of F. proliferatum strain PG-CH1 to Se with certainty. For this purpose, $\mathrm{NaCl}$ was added to the growth medium at the concentration of $254 \mathrm{mg} \mathrm{kg}^{-1}$ to fix the amount of $\mathrm{Na}^{+}$at $100 \mathrm{mg} \mathrm{kg}^{-1}$, which is the same as the maximum Se concentration used in the experiment. Furthermore, the selected concentration of $254 \mathrm{mg} \mathrm{kg}^{-1}$ of $\mathrm{NaCl}\left(100 \mathrm{mg} \mathrm{kg}^{-1}\right.$ of $\mathrm{Na}^{+}$) allowed the concentration of $\mathrm{Na}^{+}$combined with inorganic Se (selenite and selenate) to be exceeded. After 10 days of incubation at $22 \pm 2{ }^{\circ} \mathrm{C}$ in the dark, radial growth of fungal colonies was measured by ImageJ software (https: / /imagej.nih.gov/ij/, accessed on 20 January 2019), and the inhibitory activity was expressed as the percentage of radial growth reduction concerning the untreated control, according to Equation (1):

$$
\begin{aligned}
& \text { Radial growth reduction of F. proliferatum strain PG }- \text { CH1colonies }(\%)= \\
& \text { (radial growth } \left._{\text {control }}-\text { radial growth } \text { treatment }\right) \text { : radial growth } \mathrm{control}_{\mathrm{c}} \times 100
\end{aligned}
$$

Four replicates per treatment were performed. This experiment was repeated twice and the results of the second experiment, representative of the entire study, are shown. The preliminary first experiment showed a colony growth pattern, which was confirmed by the results obtained in the second experiment. The following analyses were realized exclusively using the materials of the second experiment.

\subsection{Se Speciation Analysis}

The Se speciation analysis was performed on 10 day old F. proliferatum colonies grown on amended PDA. About $16 \mathrm{~g}$ of sample (the sample comprises both mycelium and growth medium) was added with $10 \mathrm{~mL}$ of distilled water to $50 \mathrm{~mL}$ centrifuge tubes, accurately stirred to disperse the PDA gel, and sonicated for $2 \mathrm{~min}$ with an ultrasound probe. Then, protease was added up to $2.0 \mathrm{mg} \mathrm{mL}^{-1}$ and the obtained sample was stirred in a water bath at $37^{\circ} \mathrm{C}$ for $15 \mathrm{~h}$. Because PDA contained $2 \%$ by weight of agar, and considering that agar forms a gel in the concentration range of $0.5-2 \%$ by weight, the obtained samples were 10 -fold diluted with distilled water, then cooled at room temperature and centrifuged at $5000 \mathrm{rpm}$ for $10 \mathrm{~min}$. Then, the supernatant was collected and filtered through $0.22 \mu \mathrm{m}$ Millex GV filters (Millipore Corporation). The Se standards selenite, selenate, Se-Met, and Se-Cys were prepared in ultrapure ( $>18 \mathrm{M} \Omega$ ) water (Supplementary Figure S2). Speciation of Se was performed using a Liquid Chromatography-Inductively Coupled Plasma Mass Spectrometry (LC-ICP-MS/MS) system consisting of an Agilent 1260 Infinity II LC system and an Agilent 8900 ICP-tandem mass spectrometer (Agilent Technologies Japan, Ltd., Tokyo, Japan). Details of the mobile phases, column, and MS/MS conditions are available in Supplementary Table S1.

\subsection{Observation by Scanning Electron Microscopy}

For this analysis, based on the results obtained from in vitro evaluation of the inhibitory activity of different Se forms on F. proliferatum strain PG-CH1 growth, we focused our attention on Se activity from selenite. In detail, a mycelium plug ( $5 \mathrm{~mm}$ diameter) of F. proliferatum developed in the presence of $0,5,10,15,20$, and $100 \mathrm{mg} \mathrm{kg}^{-1}$ of Se from selenite was sampled from 10 day old colonies to perform SEM analysis. A mycelium plug was collected from two replicates of the previously described experiment for a total of 12 samples (5 different Se concentrations from selenite plus the untreated control). Samples were prepared for SEM observations following the protocol described in [73] with slight modifications. Samples were fixed in 5\% glutaraldehyde for $24 \mathrm{~h}$; washed three times with $0.1 \mathrm{M}$ phosphate buffer, $\mathrm{pH} 7.2$; rinsed three times in distilled water; and dehydrated in ethanol series $(25 \%, 50 \%, 75 \%, 90 \%$, and $100 \%)$ for 7 min each. Samples were then 
transferred to a critical point dryer (Emitech K850, Quorum Technologies Ltd., Laughton, UK) to complete the drying process with carbon dioxide as a transition fluid. Specimens were then mounted on aluminum stubs with double-sided carbon tape, coated with gold in a sputter (Emitech K500, Quorum Technologies Ltd., Tokyo, Japan), and observed with a SEM 515 (Philips, Amsterdam, The Netherlands) at $12 \mathrm{kV}$. Observations were conducted for all 12 samples.

\subsection{Statistical Analysis}

Data of radial growth reduction of $F$. proliferatum strain PG-CH1 colonies after 10 days of incubation at $22 \pm 2{ }^{\circ} \mathrm{C}$ in the dark in the presence of different Se concentrations from different Se forms were subject to one-way ANOVA. Data were analyzed considering the "radial growth reduction of F. proliferatum strain PG-CH1 colonies" (variable) for each "Se concentration" or "Se form" (factors). The results were expressed as the mean of four biological replicates ( \pm standard error). To check for pairwise contrasts, Tukey Honestly Significant Difference multiple comparison tests were performed $(p<0.05)$ using the Microsoft Excel (Microsoft Corporation, Redmond, WA, USA) Macro "DSAASTAT ver. 1.0192" (macro developed by University of Perugia, Italy) [74].

Supplementary Materials: The following are available online at https://www.mdpi.com/article/ 10.3390/plants10081725/s1, Figure S1. Comparison between Fusarium proliferatum strain PG-CH1 development on untreated potato dextrose agar (PDA) (untreated control; a,d), on PDA amended with $100 \mathrm{mg} \mathrm{kg}^{-1}$ of Selenium from sodium selenite (b), sodium selenate (e), and on PDA amended with $100 \mathrm{mg} \mathrm{kg}^{-1}$ of $\mathrm{Na}^{+}$from $\mathrm{NaCl}(\mathrm{c}, \mathrm{f})$ (control treatment). Figure S2. Liquid chromatographyinductively coupled plasma mass spectrometry (LC-ICP-MS/MS) chromatogram of $1 \mu \mathrm{g} \mathrm{L}{ }^{-1}$ of selenium standards. Peak identities are selenocystine (a), selenomethionine (b), sodium selenite (c), and sodium selenate (d). Table S1: Liquid chromatography-inductively coupled plasma mass spectrometry (LC-ICP-MS/MS) conditions.

Author Contributions: Conceptualization, G.B., R.D., D.B. (Daniela Businelli) and L.C.; methodology, E.T., G.B., R.D., G.M.B. and M.C.F.; formal analysis, E.T., G.B. and R.D.; investigation, E.T., G.B., R.D., F.T., D.B. (David Baldo), M.T.S., G.M.B., M.C.F. and A.P.; resources, D.B. (Daniela Businelli) and L.C.; data curation, E.T., G.B., R.D. and F.T.; writing—original draft preparation, E.T., G.B. and R.D.; writing—review and editing, F.T., D.B. (Daniela Businelli) and L.C.; visualization, E.T., G.B., R.D., D.B. (David Baldo), M.T.S. and A.P.; supervision, D.B. (Daniela Businelli) and L.C. All authors have read and agreed to the published version of the manuscript.

Funding: This research received no external funding.

Acknowledgments: Graphical abstract was created with Biorender.com, accessed on 1 July 2021.

Conflicts of Interest: The authors declare no conflict of interest.

\section{References}

1. Steinbrenner, H.; Speckmann, B.; Klotz, L.O. Selenoproteins: Antioxidant selenoenzymes and beyond. Arch. Biochem. Biophys. 2016, 595, 113-119. [CrossRef]

2. Roman, M.; Jitaru, P.; Barbante, C. Selenium biochemistry and its role for human health. Metallomics 2014, 6, 25-54. [CrossRef]

3. D'Amato, R.; Regni, L.; Falcinelli, B.; Mattioli, S.; Benincasa, P.; Dal Bosco, A.; Pacheco, P.; Proietti, P.; Troni, E.; Santi, C.; et al. Current knowledge on selenium biofortification to improve the nutraceutical profile of food: A comprehensive review. J. Agric. Food Chem. 2020, 68, 4075-4097. [CrossRef]

4. Ursini, F.; Maiorino, M. Glutathione peroxidases. In Encyclopedia of Biological Chemistry, 2nd ed.; Elsevier Inc.: Amsterdam, The Netherlands, 2013; pp. 399-404.

5. Gupta, M.; Gupta, S. An overview of selenium uptake, metabolism, and toxicity in plants. Front Plant. Sci. 2017, 7, 2074. [CrossRef]

6. Vats, S. Biotic and Abiotic Stress Tolerance in Plants; Vats, S., Ed.; Springer: Singapore; Springer Nature Singapore Pte Ltd.: Singapore, 2018.

7. Hasanuzzaman, M.; Bhuyan, M.H.M.B.; Raza, A.; Hawrylak-Nowak, B.; Matraszek-Gawron, R.; Mahmud, J.A.; Nahar, K.; Fujita, M. Selenium in plants: Boon or bane? Environ. Exp. Bot. 2020, 178, 104170. [CrossRef] 
8. Hasanuzzaman, M.; Borhannuddin Bhuyan, M.H.M.; Raza, A.; Hawrylak-Nowak, B.; Matraszek-Gawron, R.; Nahar, K.; Fujita, M. Selenium toxicity in plants and environment: Biogeochemistry and remediation possibilities. Plants 2020, 9, 1711. [CrossRef] [PubMed]

9. Kuznetsov, V.; Kuznetsov, V. Selenium regulates the water status of plants exposed to drought. Dokl. Biol. Sci. 2003, 390, 266-268. [CrossRef] [PubMed]

10. Gilmara, P.d.S.; Leonardo, C.C.; Victor, V.C.; Sylvia, L.O.S.; Edilaine, I.F.T. Selenium and agricultural crops. Afr. J. Agric. Res. 2017, 12, 2545-2554. [CrossRef]

11. Bocchini, M.; D’Amato, R.; Ciancaleoni, S.; Fontanella, M.C.; Palmerini, C.A.; Beone, G.M.; Onofri, A.; Negri, V.; Marconi, G.; Albertini, E.; et al. Soil Selenium (Se) biofortification changes the physiological, biochemical and epigenetic responses to water stress in Zea mays L. by inducing a higher drought tolerance. Front. Plant Sci. 2018, 9, 389. [CrossRef] [PubMed]

12. Proietti, P.; Nasini, L.; Del Buono, D.; D'Amato, R.; Tedeschini, E.; Businelli, D. Selenium protects olive (Olea europaea L.) from drought stress. Sci. Hortic. 2013, 164, 165-171. [CrossRef]

13. Feng, R.; Wei, C.; Tu, S. The roles of selenium in protecting plants against abiotic stresses. Environ. Exp. Bot. 2013, 87, 58-68. [CrossRef]

14. Rayman, M.P. Selenium intake, status, and health: A complex relationship. Hormones 2019, 19, 9-14. [CrossRef] [PubMed]

15. Thiry, C.; Ruttens, A.; De Temmerman, L.; Schneider, Y.J.; Pussemier, L. Current knowledge in species-related bioavailability of selenium in food. Food Chem. 2012, 130, 767-784. [CrossRef]

16. Bhatia, P.; Aureli, F.; D'Amato, M.; Prakash, R.; Cameotra, S.S.; Nagaraja, T.P.; Cubadda, F. Selenium bioaccessibility and speciation in biofortified Pleurotus mushrooms grown on selenium-rich agricultural residues. Food Chem. 2013, 140, 225-230. [CrossRef]

17. Hasanuzzam, M.; Hossain, M.A.; Fujita, M. Selenium in higher plants: Physiological role, antioxidant metabolism and abiotic stress tolerance. J. Plant Sci. 2010, 5, 354-375. [CrossRef]

18. Wu, Z.-L.; Yin, X.-B.; Lin, Z.-Q.; Bañuelos, G.S.; Yuan, L.-X.; Liu, Y.; Li, M. Inhibitory effect of selenium against Penicillium expansum and its possible mechanisms of action. Curr. Microbiol. 2014, 69, 192-201. [CrossRef] [PubMed]

19. Razak, A.A.; El-Tantawy, H.; El-Sheikh, H.H.; Gharieb, M.M. Influence of selenium on the efficiency of fungicide action against certain fungi. Biol. Trace Elem. Res. 1991, 28, 47-56. [CrossRef] [PubMed]

20. Ramadan, S.E.; Razak, A.A.; Yousseff, Y.A.; Sedky, N.M. Selenium metabolism in a strain of Fusarium. Biol. Trace Elem. Res. 1988, 18, 161-170. [CrossRef] [PubMed]

21. Mao, X.; Hua, C.; Yang, L.; Zhang, Y.; Sun, Z.; Li, L.; Li, T. The effects of selenium on wheat fusarium head blight and DON accumulation were selenium compound-dependent. Toxins 2020, 12, 573. [CrossRef] [PubMed]

22. Hanson, B.; Garifullina, G.F.; Lindblom, S.D.; Wangeline, A.; Ackley, A.; Kramer, K.; Norton, A.P.; Lawrence, C.B.; Pilon-Smits, E.A.H. Selenium accumulation protects Brassica juncea from invertebrate herbivory and fungal infection. New Phytol. 2003, 159, 461-469. [CrossRef] [PubMed]

23. Companioni, B.; Medrano, J.; Torres, J.A.; Flores, A.; Rodríguez, E.; Benavides, A. Protective action of sodium selenite against Fusarium wilt in tomato: Total protein contents, levels of phenolic compounds and changes in antioxidant potential. Acta Hortic. 2012, 947, 321-327. [CrossRef]

24. You, J.; Zhang, J.; Wu, M.; Yang, L.; Chen, W.; Li, G. Multiple criteria-based screening of Trichoderma isolates for biological control of Botrytis cinerea on tomato. Biol. Control. 2016, 101, 31-38. [CrossRef]

25. Filek, M.; Łabanowska, M.; Kurdziel, M.; Sieprawska, A. Electron paramagnetic resonance (EPR) spectroscopy in studies of the protective effects of 24-epibrasinoide and selenium against zearalenone-stimulation of the oxidative stress in germinating grains of wheat. Toxins 2017, 9, 178. [CrossRef] [PubMed]

26. Kornaś, A.; Filek, M.; Sieprawska, A.; Bednarska-Kozakiewicz, E.; Gawrońska, K.; Miszalski, Z. Foliar application of selenium for protection against the first stages of mycotoxin infection of crop plant leaves. J. Sci. Food Agric. 2019, 99, 482-485. [CrossRef] [PubMed]

27. Agar, G.; Alpsoy, L.; Bozari, S.; Erturk, F.A.; Yildirim, N. Determination of protective role of selenium against aflatoxin B1-induced DNA damage. Toxicol. Ind. Health 2013, 29, 396-403. [CrossRef] [PubMed]

28. Liu, X.; Zhao, Z.; Duan, B.; Hu, C.; Zhao, X.; Guo, Z. Effect of applied sulphur on the uptake by wheat of selenium applied as selenite. Plant Soil 2015, 386, 35-45. [CrossRef]

29. D'Amato, R.; Fontanella, M.C.; Falcinelli, B.; Beone, G.M.; Bravi, E.; Marconi, O.; Benincasa, P.; Businelli, D. Selenium biofortification in rice (Oryza sativa L.) sprouting: Effects on Se yield and nutritional traits with focus on phenolic acid profile. J. Agric. Food Chem. 2018, 66, 4082-4090. [CrossRef]

30. Kane, C.D.; Jasoni, R.L.; Peffley, E.P.; Thompson, L.D.; Green, C.J.; Pare, P.; Tissue, D. Nutrient solution and solution pH influences on onion growth and mineral content. J. Plant Nutr. 2006, 29, 375-390. [CrossRef]

31. O’Donnell, K.; Nirenberg, H.I.; Aoki, T.; Cigelnik, E. A Multigene phylogeny of the Gibberella fujikuroi species complex: Detection of additional phylogenetically distinct species. Mycoscience 2000, 41, 61-78. [CrossRef]

32. O’Donnell, K.; Rooney, A.P.; Proctor, R.H.; Brown, D.W.; McCormick, S.P.; Ward, T.J.; Frandsen, R.J.N.; Lysøe, E.; Rehner, S.A.; Aoki, T.; et al. Phylogenetic analyses of RPB1 and RPB2 support a middle Cretaceous origin for a clade comprising all agriculturally and medically important fusaria. Fungal Genet. Biol. 2013, 52, 20-31. [CrossRef] 
33. Palacios, S.A.; Susca, A.; Haidukowski, M.; Stea, G.; Cendoya, E.; Ramírez, M.L.; Chulze, S.N.; Farnochi, M.C.; Moretti, A.; Torres, A.M. Genetic variability and fumonisin production by Fusarium proliferatum isolated from durum wheat grains in Argentina. Int. J. Food Microbiol. 2015, 201, 35-41. [CrossRef]

34. Chulze, S.N.; Ramirez, M.L.; Farnochi, M.C.; Pascale, M.; Visconti, A.; March, G. Fusarium and fumonisin occurrence in Argentinian corn at different ear maturity stages. J. Agric. Food Chem. 1996, 44, 2797-2801. [CrossRef]

35. Amatulli, M.T.; Spadaro, D.; Gullino, M.L.; Garibaldi, A. Molecular identification of Fusarium spp. associated with bakanae disease of rice in Italy and assessment of their pathogenicity. Plant Pathol. 2010, 59, 839-844. [CrossRef]

36. Wulff, E.G.; Sørensen, J.L.; Lübeck, M.; Nielsen, K.F.; Thrane, U.; Torp, J. Fusarium spp. associated with rice Bakanae: Ecology, genetic diversity, pathogenicity and toxigenicity. Environ. Microbiol. 2010, 12, 649-657. [CrossRef] [PubMed]

37. Leslie, J.F.; Zeller, K.A.; Lamprecht, S.C.; Rheeder, J.P.; Marasas, W.F.O. Toxicity, pathogenicity, and genetic differentiation of five species of Fusarium from sorghum and millet. Phytopathology 2005, 95, 275-283. [CrossRef]

38. Vismer, H.F.; Shephard, G.S.; van der Westhuizen, L.; Mngqawa, P.; Bushula-Njah, V.; Leslie, J.F. Mycotoxins produced by Fusarium proliferatum and F. pseudonygamai on maize, sorghum and pearl millet grains in vitro. Int. J. Food Microbiol. 2019, 296, 31-36. [CrossRef]

39. Logrieco, A.; Doko, B.; Moretti, A.; Frisullo, S.; Visconti, A. Occurrence of fumonisin B1 and B2 in Fusarium proliferatum infected asparagus plants. J. Agric. Food Chem. 1998, 46, 5201-5204. [CrossRef]

40. Gálvez, L.; Urbaniak, M.; Waśkiewicz, A.; Stępień, Ł.; Palmero, D. Fusarium proliferatum-Causal agent of garlic bulb rot in Spain: Genetic variability and mycotoxin production. Food Microbiol. 2017, 67, 41-48. [CrossRef]

41. Abdalla, M.Y.; Al-Rokibah, A.; Moretti, A.; Mulè, G. Pathogenicity of toxigenic Fusarium proliferatum from date palm in Saudi Arabia. Plant Dis. 2000, 84, 321-324. [CrossRef] [PubMed]

42. Desjardins, A.E.; Manandhar, H.K.; Plattner, R.D.; Manandhar, G.G.; Poling, S.M.; Maragos, C.M. Fusarium species from nepalese rice and production of mycotoxins and gibberellic acid by selected species. Appl. Environ. Microbiol. 2000, 66, 1020-1025. [CrossRef] [PubMed]

43. Mohd Zainudin, N.A.I.; Razak, A.A.; Salleh, B. Bakanae disease of rice in malaysia and indonesia: Etiology of the causal agent based on morphological, physiological and pathogenicity characteristics. J. Plant Prot. Res. 2008, 48, 475-485. [CrossRef]

44. Ji, F.; He, D.; Olaniran, A.O.; Mokoena, M.P.; Xu, J.; Shi, J. Occurrence, toxicity, production and detection of Fusarium mycotoxin: A review. Food Prod. Process. Nutr. 2019, 1, 1-14. [CrossRef]

45. Braun, M.S.; Wink, M. Exposure, occurrence, and chemistry of fumonisins and their cryptic derivatives. Compr. Rev. Food Sci. Food Saf. 2018, 17, 769-791. [CrossRef]

46. Schiavon, M.; Nardi, S.; dalla Vecchia, F.; Ertani, A. Selenium biofortification in the 21st century: Status and challenges for healthy human nutrition. Plant Soil 2020, 453, 245-270. [CrossRef] [PubMed]

47. Reddy, C.C.; Massaro, E.J. Biochemistry of selenium: A brief overview. Toxicol. Sci. 1983, 3, 431-436. [CrossRef]

48. McNeal, J.M.; Balistrieri, L.S. Geochemistry and Occurrence of Selenium: An Overview. In Selenium in Agriculture and the Environment; Jacob, L.W., Ed.; Soil Science Society of America: Madison, WI, USA, 1989; pp. 1-13.

49. Boyd, R. Selenium stories. Nat. Chem. 2011, 3, 570. [CrossRef]

50. Wu, Z.; Yin, X.; Bañuelos, G.S.; Lin, Z.Q.; Zhu, Z.; Liu, Y.; Yuan, L.; Li, M. Effect of selenium on control of postharvest gray mold of tomato fruit and the possible mechanisms involved. Front. Microbiol. 2016, 6, 1-11. [CrossRef] [PubMed]

51. Yin, H.; Zhang, Y.; Zhang, F.; Hu, J.T.; Zhao, Y.M.; Cheng, B.L. Effects of selenium on Fusarium growth and associated fermentation products and the relationship with chondrocyte viability. Biomed. Environ. Sci. 2017, 30, 134-138. [PubMed]

52. Jacob, C.; Giles, G.I.; Giles, G.I.; Sies, H. Sulfur and selenium: The role of oxidation state in protein structure and function. Angew. Chem. Int. Ed. 2003, 42, 4742-4758. [CrossRef] [PubMed]

53. Läuchli, A. Selenium in plants: Uptake, functions, and environmental toxicity. Bot. Acta 1993, 106, 455-468. [CrossRef]

54. Patching, S.G.; Gardiner, P.H.E. Recent developments in selenium metabolism and chemical speciation: A review. J. Trace Elem. Med. Biol. 1999, 13, 193-214. [CrossRef]

55. Georgiou, C.D.; Patsoukis, N.; Papapostolou, I.; Zervoudakis, G. Sclerotial metamorphosis in filamentous fungi is induced by oxidative stress. Integr. Comp. Biol. 2006, 46, 691-712. [CrossRef]

56. Brown, T.A.; Shrift, A. Selenium: Toxicity and tolerance in higher plants. Biol. Rev. 1982, 57, 59-84. [CrossRef]

57. da Silva, M.d.C.S.; da Luz, J.M.R.; Paiva, A.P.S.; Mendes, D.R.; Carvalho, A.A.C.; Naozuka, J.; Kasuya, M.C.M. Growth and Tolerance of Pleurotus ostreatus at Different Selenium Forms. J. Agric. Sci. 2019, 11, 151. [CrossRef]

58. Herrero, E.; Wellinger, R.E. Yeast as a model system to study metabolic impact of selenium compounds. Microb. Cell 2015, 2, 139-149. [CrossRef] [PubMed]

59. Rao, Y.; McCooeye, M.; Windust, A.; Bramanti, E.; D’Ulivo, A.; Mester, Z. Mapping of selenium metabolic pathway in yeast by Liquid Chromatography-Orbitrap Mass Spectrometry. Anal. Chem. 2010, 82, 8121-8130. [CrossRef]

60. Arnaudguilhem, C.; Bierla, K.; Ouerdane, L.; Preud'homme, H.; Yiannikouris, A.; Lobinski, R. Selenium metabolomics in yeast using complementary reversed-phase/hydrophilic ion interaction (HILIC) liquid chromatography-electrospray hybrid quadrupole trap/Orbitrap mass spectrometry. Anal. Chim. Acta 2012, 757, 26-38. [CrossRef] [PubMed]

61. Rosenfield, C.E.; Kenyon, J.A.; James, B.R.; Santelli, C.M. Selenium (IV, VI) reduction and tolerance by fungi in an oxic environment. Geobiology 2016, 15, 441-452. [CrossRef] [PubMed] 
62. Ma, Y.; Liu, R.; Gong, X.; Li, Z.; Huang, Q.; Wang, H.; Song, G. Synthesis and herbicidal activity of N,N-diethyl-3-(arylselenonyl)-1 H-1,2,4-triazole-1 -carboxamide. J. Agric. Food Chem. 2006, 54, 7724-7728. [CrossRef] [PubMed]

63. Singh, P.K. Synthesis and fungicidal activity of novel 3-(substituted/unsubstituted phenylselenonyl)-1-ribosyl/deoxyribosyl-1 H -1,2,4-triazole. J. Agric. Food Chem. 2012, 60, 5813-5818. [CrossRef]

64. Zhu, Y.G.; Pilon-Smits, E.A.H.; Zhao, F.J.; Williams, P.N.; Meharg, A.A. Selenium in higher plants: Understanding mechanisms for biofortification and phytoremediation. Trends Plant Sci. 2009, 14, 436-442. [CrossRef] [PubMed]

65. Hartikainen, H. Biogeochemistry of selenium and its impact on food chain quality and human health. J. Trace Elem. Med. Biol. 2005, 18, 309-318. [CrossRef] [PubMed]

66. Beccari, G.; Senatore, M.T.; Tini, F.; Sulyok, M.; Covarelli, L. Fungal community, Fusarium head blight complex and secondary metabolites associated with malting barley grains harvested in Umbria, central Italy. Int. J. Food Microbiol. 2018, 273 , 33-42. [CrossRef]

67. Beccari, G.; Prodi, A.; Senatore, M.T.; Balmas, V.; Tini, F.; Onofri, A.; Pedini, L.; Sulyok, M.; Brocca, L.; Covarelli, L. Cultivation area affects the presence of fungal communities and secondary metabolites in Italian durum wheat grains. Toxins 2020, 12, 97. [CrossRef] [PubMed]

68. O'Donnell, K.; Kistler, H.C.; Cigelnik, E.; Ploetz, R.C. Multiple evolutionary origins of the fungus causing panama disease of banana: Concordant evidence from nuclear and mitochondrial gene genealogies. Proc. Natl. Acad. Sci. USA 1998, 95, $2044-2049$. [CrossRef]

69. National Center for Biotechnology Information (NCBI) Basic Local Search (BLAST) Tool. Available online: http:/ / blast.ncbi.nlm. nih.gov (accessed on 1 November 2018).

70. Amatulli, M.T.; Spadaro, D.; Gullino, M.L.; Garibaldi, A. Conventional and real-time PCR for the identification of Fusarium fujikuroi and Fusarium proliferatum from diseased rice tissues and seeds. Eur. J. Plant Pathol. 2012, 134, 401-408. [CrossRef]

71. Kumar, S.; Stecher, G.; Tamura, K. MEGA7: Molecular Evolutionary Genetics Analysis Version 7.0 for Bigger Datasets. Mol. Biol. Evol. 2016, 33, 1870-1874. [CrossRef]

72. O'Donnell, K.; McCormick, S.P.; Busman, M.; Proctor, R.H.; Ward, T.J.; Doehring, G.; Geiser, D.M.; Alberts, J.F.; Rheeder, J.P.; Marasas; et al. 1984 "Toxigenic Fusarium species: Identity and mycotoxicology" revisited. Mycologia 2018, 110, 1058-1080. [CrossRef]

73. Alves, E.; Lucas, G.C.; Pozza, E.A.; de Carvalho Alves, M. Scanning electron microscopy for fungal sample examination. In Laboratory Protocols in Fungal Biology; Springer: New York, NY, USA, 2013; pp. 133-150.

74. Onofri, A.; Pannacci, E. Spreadsheet tools for biometry classes in crop science programmes. Commun. Biometry Crop. Sci. 2014, 9 , 3-13. 